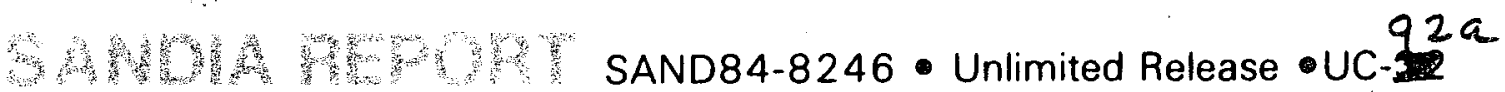

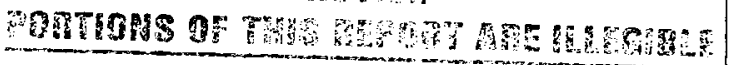

\title{
Implemention of Empirical Total Pressure Loss Data into the DUCTFLO and TOPAZ Gas Transfer Codes
}

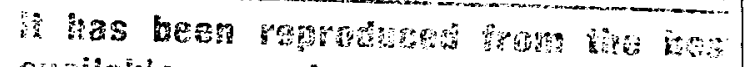

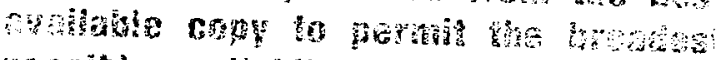

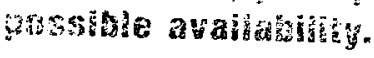

W. S. Winters and M. P. Kanouff

Prepared by

Sandta National Laboratories

Albuquerque, New Mexico 87185 and Livermore. Californa 94550

lor the United States Department of Energr

under Contract DE-AC04-76DPO0789 


\section{DISCLAIMER}

This report was prepared as an account of work sponsored by an agency of the United States Government. Neither the United States Government nor any agency Thereof, nor any of their employees, makes any warranty, express or implied, or assumes any legal liability or responsibility for the accuracy, completeness, or usefulness of any information, apparatus, product, or process disclosed, or represents that its use would not infringe privately owned rights. Reference herein to any specific commercial product, process, or service by trade name, trademark, manufacturer, or otherwise does not necessarily constitute or imply its endorsement, recommendation, or favoring by the United States Government or any agency thereof. The views and opinions of authors expressed herein do not necessarily state or reflect those of the United States Government or any agency thereof. 


\section{DISCLAIMER}

Portions of this document may be illegible in electronic image products. Images are produced from the best available original document. 

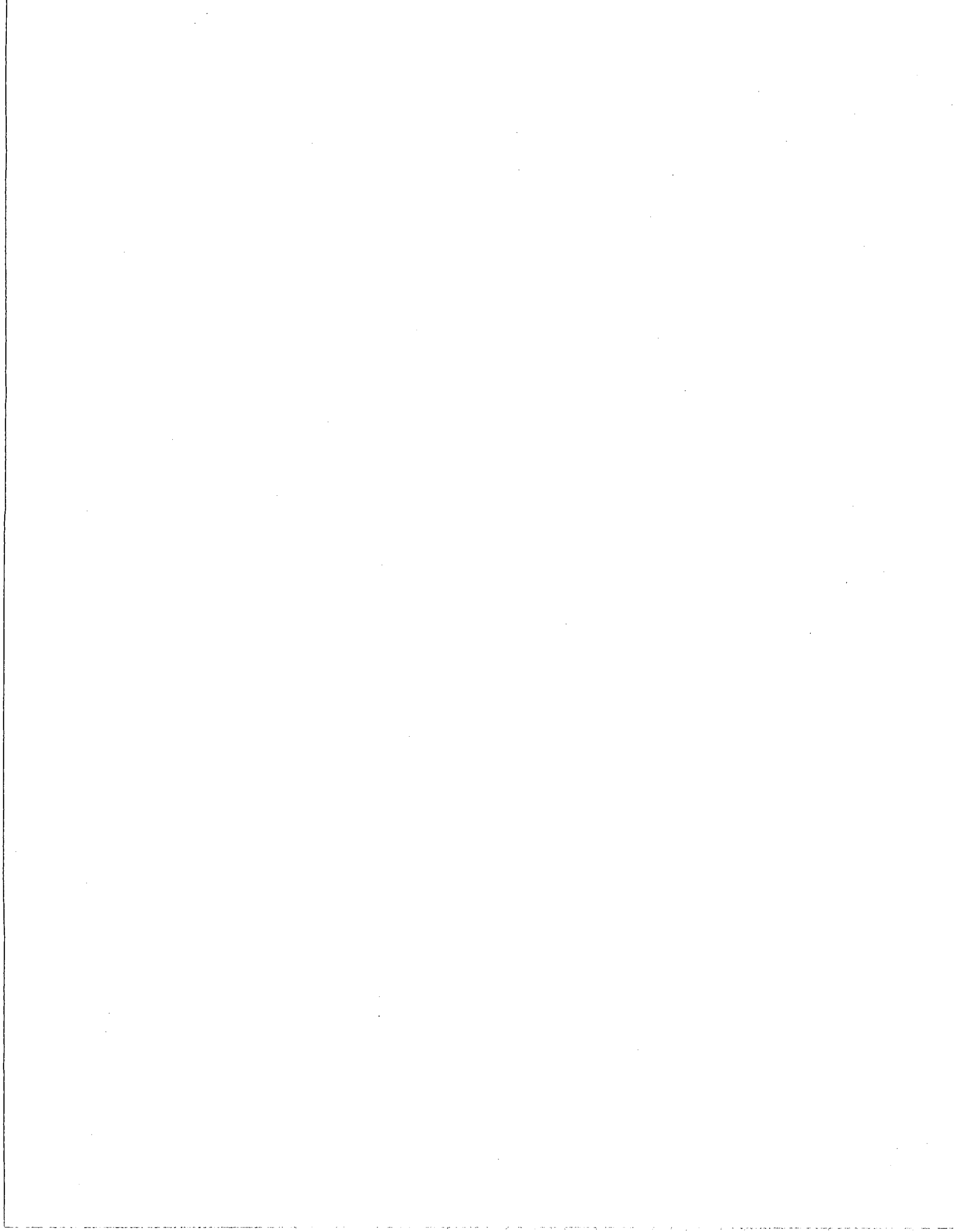
SAND84- 8246

Unlimited Release

Printed November 1984

\author{
Implemention of Empirical Total Pressure \\ Loss Data into the DUCTFLO and TOPAZ Gas \\ Transfer Codes \\ W. S. Winters \\ Analytical Thermal/Fluid Mechanics Division \\ and \\ M. P. Kanouff \\ Experimental Thermal/Fluid Mechanics Division \\ Manuscript Completed November 1983
}

\begin{abstract}
Sandia presently has two computer codes capable of modeling local pressure and enthalpy losses in lines connecting gas reservoirs and recejvers. Each code conserves flow continuity, momentum, and energy as a function of position along the flow path. The first of these codes, DUCTFLO, models gas flow by solving a set of coupled algebraic equations. The DUCTFLO code has been formulated to make direct use of laboratory total pressure and enthalpy loss data. The second code, TOPAZ, models gas flow by solving a set of coupled ordinary differential equations using a conventional finite difference technique. The TOPAZ finite difference equations must be altered slightly in order to make use of laboratory total pressure and enthalpy loss data. In this report, methods for implementing empirical loss data in the two codes are discussed. In quasi-steady flow situations, it is shown that the two codes predict the same gas transfer for a given set of empirical loss data. This is demonstrated in an example problem consisting of a reservoir and receiver connected by a series of seven flow components each having unique loss characteristics.
\end{abstract}

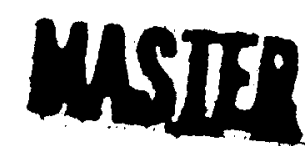

ep 



\section{Contents}

I. Introduction

Page

II. Total Losses Method

$13 / 14$

III. Discussion of DUCTFLO

15

IV. Discussion of TOPAZ 21

1. Introduction 21

2. Incorporating Total Pressure Loss Data 24

3. Incorporating Total Enthalpy Loss Data 25/26

V. Comparison of DUCTFLO and TOPAZ Calculations 27

1. Test Problem 27

2. Calculated Results 27

$\begin{array}{ll}\text { VI. References } & 35\end{array}$ 



\section{List of Figures}

Figure 1. Typical gas transfer sy stem schematic $\frac{\text { Page }}{16}$

Figure 2. TOPAZ nodalization for components 23

$\begin{array}{lll}\text { Figure 3. Example problem schematic } & 28\end{array}$

Figure 4. Vessel pressure histories for example problem 31

Figure 5. Vessel temperature histories for example problem 32

Figure 6. Vessel mass inventories for example problem 33 

List of Tables

Table I. Loss Parameters for Example Problem $\frac{\text { Page }}{29}$

Table II. Reservoir/Receiver Parameters for Example Problem 30 


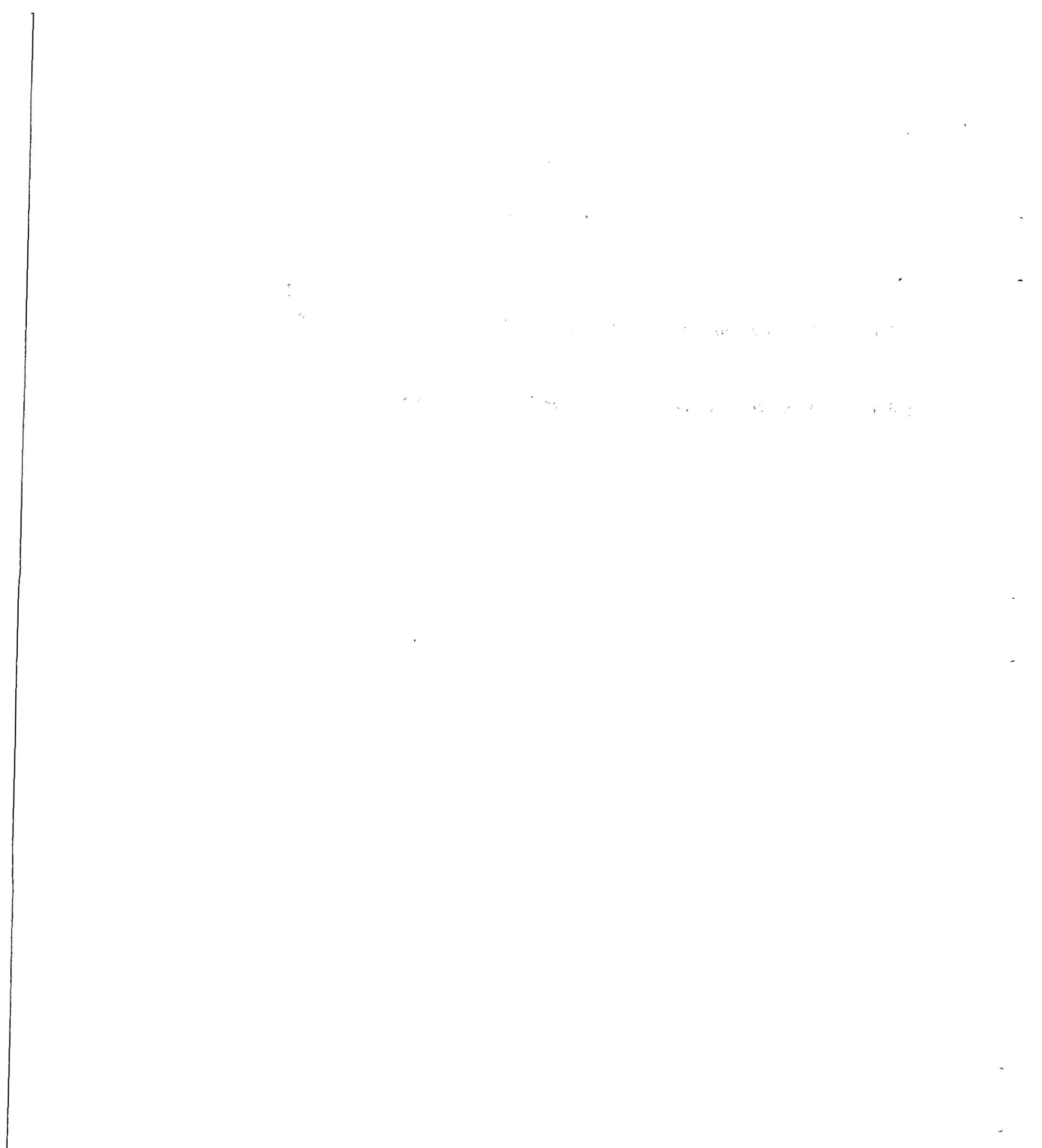




\section{Nomenclature}

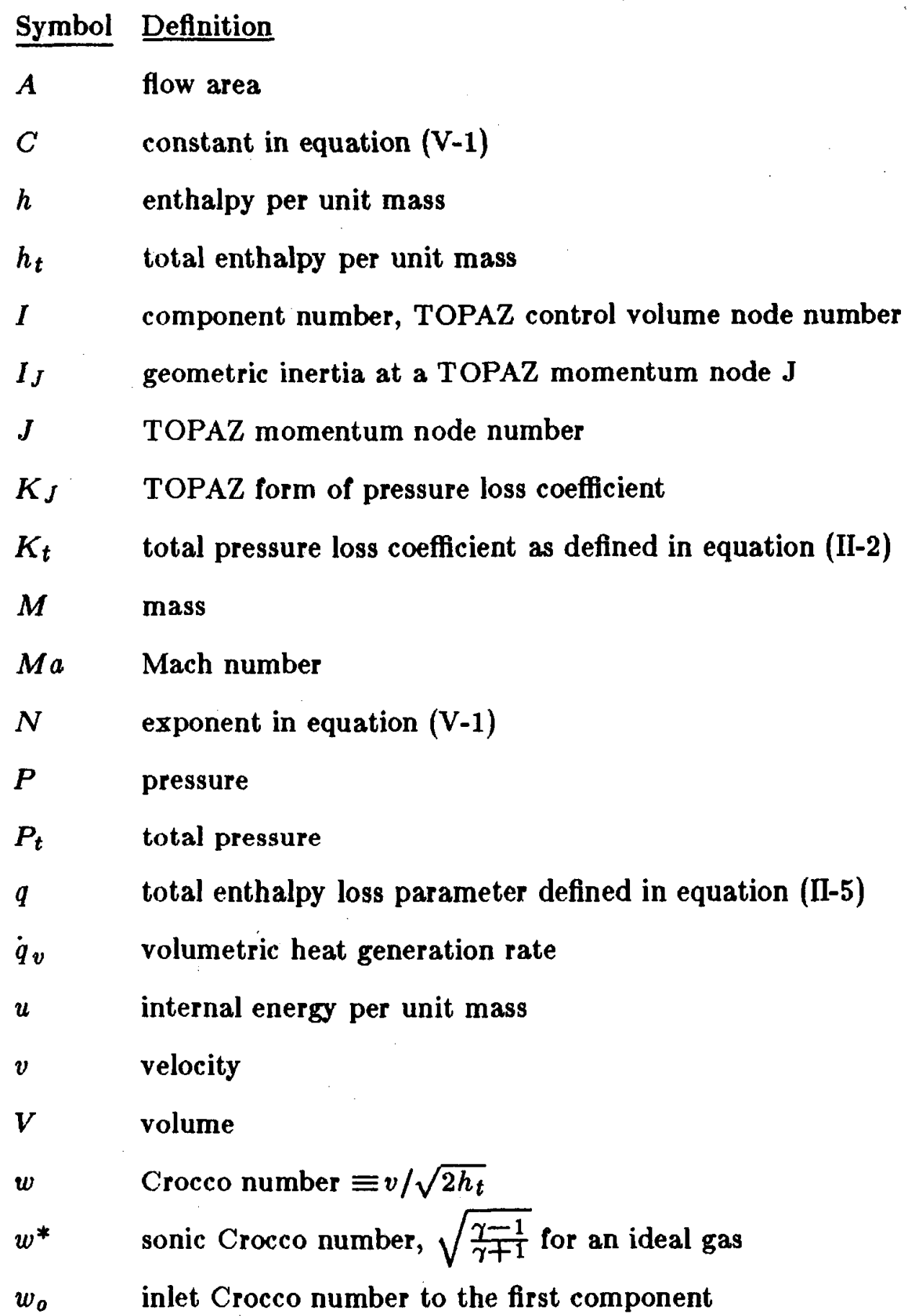




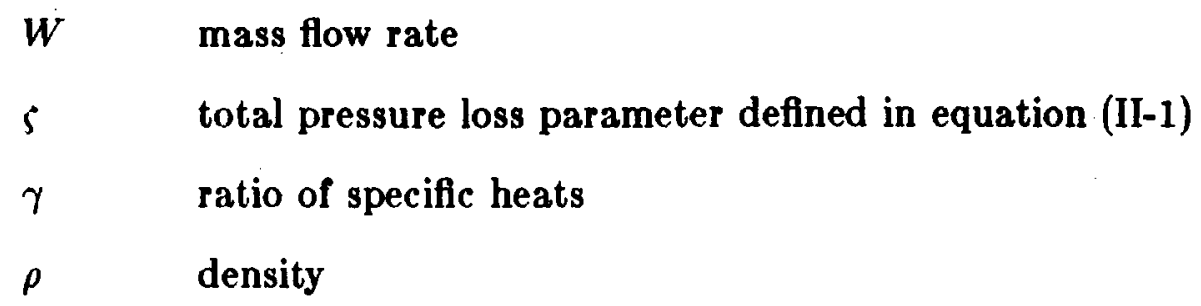




\section{Introduction}

In this report a method [1,12] for characterizing pressure and enthalpy losses in gas transfer systems is reviewed. The method suggests a particular strategy for obtaining experimental loss data in terms of total pressure and enthalpy (or temperature) changes in the system. Section II contains a brief description of the method, which for convenience, will be referred to here as the "total losses method".

When data is collected using the total losses method, a question immediately arises as to the difficulty in implementing the data into existing gas transfer codes. This is the main thrust of the present study.

Sandia presently has two computer codes capable of implementing experimental pressure and enthalpy loss data into numerical gas transfer predictions. These codes, DUCTFLO and TOPAZ, are discussed in Sections III and IV, respectively. It is shown that the first of these codes, DUCTFLO, is specifically designed to directly implement data collected using the total losses method. The second code, TOPAZ, is a traditional finite difference code which requires modification in order to implement the same data.

In Section $V$ it is shown that once minor modifications are made to TOPAZ, both codes predict the same gas transfer for a given set of empirical total loss data. This is demonstrated in an example problem consisting of a reservoir and receiver connected by a series of seven flow components, each having unique loss characteristics. 



\section{Total Losses Method}

A typical gas transfer system is shown in Figure 1. Gas is initially stored at high pressure in the reservoir. At time zero the valve is opened and gas is allowed to flow through the connecting piping and into the receiver. The performance of the system is judged in terms of the rate of gas transfer and the amount of gas transferred in a specified time.

The discussion here will center around describing the flow in the piping connecting reservoirs and receivers. In some simple cases these quasi-steady flows can be described analytically (e.g. isentropic, Fanno line, and Rayleigh line flows [2]). As the flows become more complex one is forced to integrate the flow conservation equations numerically over the flow path. For fully developed flows through straight tubing of constant diameter, numerically integrating the conservation equations in one space dimension (axial) is sufficient. From a gas transfer analysis point of view, this represents the current state of the art. The SNLL codes DUCTFLO and TOPAZ as well as all of the generalized nuclear reactor loss of coolant analy sis codes [3-5] numerically solve the flow conservation equations in one space dimension.

More often than not, flows between reservoirs and receivers undergo direction changes, expansions, and contractions as a result of passing through valves, tees, and tube bends. Such flows are far from one-dimensional and thus cannot be analyzed with state-of-the-art 1-D codes. Finite difference computer generated solutions of multi-dimensional flows are too costly to be employed on a grand scale. Because of this, the current approach to treating complex flows with 1-D codes is to employ empirical models for pressure and enthalpy losses. Two reliable models for fully developed quasi-steady flow in straight tubes are, for example, the Moody friction factor correlation for pressure loss [6] and the Dittus-Boelter heat transfer correlation [7] which can be used to calculate enthalpy loss. A number of other empirical correlations are also available for frequently encountered multidimensional flows, e.g., references $[8,9]$.

Frequently, however, flows through networks where the bulk of the losses are due to multidimensional effects are unique and can only be accurately predicted by combining 


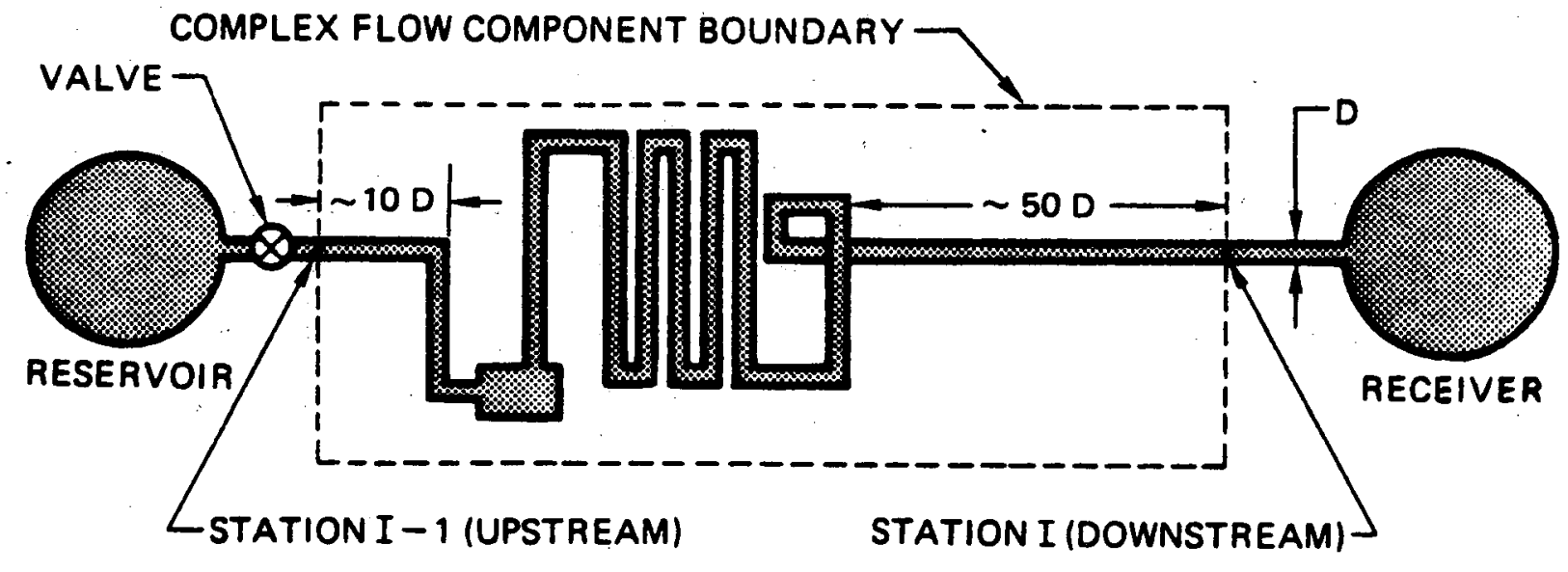

Figure 1. Typical gas transfer system schematic 
new empirical data with existing 1-D computer codes.

Figure 1 shows a flow component (actually a series of tube bends, expansions and contractions) in a line connecting a reservoir and receiver. Generally, multidimensional effects from components extend roughly 10 tube diameters upstream and 50 diameters downstream of the component. Hence all the plumbing within the dashed line is considered a single flow component. The objective in obtaining an empirical correlation is to relate the gas properties at the upstream station (I-1) to the gas properties at the downstream station (I). Indicating stations with the notation $I-1$ and $I$ is done to call attention to the fact that several flow components in series $(I=1,2,3$, etc.) could be analyzed provided appropriate empirical correlations are obtained for each component through individual experiments.

In the previously referred to "total losses method", the pressure loss through a flow component is expressed in terms of total pressures. The total pressure, $P_{t}$, is defined here as the pressure of the gas when brought to rest isentropically. The total pressure loss, 5 , occurring across a component may be expressed as

$$
\zeta \equiv \frac{\left(P_{t}\right)_{I-1}-\left(P_{t}\right)_{I}}{\left(P_{t}\right)_{I-1}} .
$$

The pressure loss coefficient, $K_{t}$, is defined

$$
K_{t} \equiv \frac{\left(P_{t}\right)_{I-1}-\left(P_{t}\right)_{I}}{\left(\rho v^{2} / 2\right)_{I-1}}
$$

For an ideal gas $\zeta$ and $K_{t}$ can be related using equation (II-3),

$$
\varsigma=K_{t}\left(\frac{\gamma}{\gamma-1}\right) w_{I-1}^{2}\left(1-w_{I-1}^{2}\right)^{\frac{1}{\gamma-1}}
$$

where $\omega$ is the Crocco number (see Nomenclature).

Heat transfer in components results in total enthalpy losses for the flowing gas. Total enthalpy is defined here as the enthalpy of the gas when brought to rest adiabatically, i.e.,

$$
h_{t}=h+\frac{v^{2}}{2} \text {. }
$$

The total enthalpy loss, $q$, may be expressed in terms of the upstream and downstream 
total enthalpy as

$$
q \equiv \frac{\left(h_{t}\right)_{I}-\left(h_{t}\right)_{I-1}}{\left(h_{t}\right)_{I-1}}
$$

In the total losses method (see e.g., reference [1]), it is proposed that laboratory measurements upstream and downstream of components be used to construct correlations for $q$ and $K_{t}$ (or $s$ ) as a function of appropriate flow parameters (e.g., $\dot{m}, M a, R e$, etc.). 


\section{Discussion of DUCTFLO}

\section{Introduction}

DUCTFLO is a family of subroutines used in conjunction with the computer code TRIC [10] for modelling gas transfer through duct systems such as depicted in Figure 1. The number of components is not restricted; however, they must be arranged in a series configuration between gas reservoirs. The gas transfer is assumed quasi-steady and the gas in the duct is assumed ideal. The design of the model is based on reference [1], which also outlines the formulations necessary to treat branching flows.

DUCTFLO calculates the mass and energy flow rates between gas reservoirs and receivers. TRIC $[10]$ is used to integrate the time-dependent continuity and energy equations for the reservoirs and receivers. TRIC uses the DUCTFLO results to perform this integration over one time step. It then updates the pressure and temperature in each reservoir and returns this information to DUCTFLO for use as boundary conditions in the gas transfer calculations. DUCTFLO then calculates updated values of the mass and energy flow rates and the procedure is repeated.

DUCTFLO uses the "total losses method" exclusively to characterize the 3-D flow effects occurring in each component. The duct is divided up into components. In keeping with the nomenclature developed in section II, the components: are assumed numbered $I=1$ to $I=N$ starting at the component bordering the reservoir and ending at the component bordering the receiver. The losses in each component, including tubes, is characterized by empirical data of the form of $\zeta$ and $q$ defined in equations II-1 and II-5, respectively.

\section{DUCTFLO Equations}

The empirical correlations for $s$ and $q$ replace the need for the momentum and energy equations; hence, the only conservation equation needed is continuity. The one-dimensional continuity equation applied to a component is given in terms of the Crocco number, $\omega$, by equation III-1: 


$$
\frac{A_{I-1}}{A_{I}} \frac{\sqrt{1+q}}{1-\varsigma} w_{I-1}\left(1-w_{I-1}^{2}\right)^{\frac{1}{\gamma-1}}=w_{I}\left(1-w_{I}^{2}\right)^{\frac{1}{\gamma^{-1}}}
$$

This equation along with the correlations for $\zeta$ and $q$ are applied to each component in the system. The unknowns for each component are the outlet Crocco number, $\omega_{I}$, and the outlet total pressure, and the outlet total enthalpy. $w_{I}, P_{t}$, and $h_{t}$ fully specify the exit flow conditions.

\section{DUCTFLO Boundary Conditions}

The upstream boundary condition is determined by the inlet $P_{t}$ and $h_{t}$ to the first component. DUCTFLO assumes the gas in the reservoir expands isentropically to the reservoir exit conditions. Hence, $P_{t}$ and $h_{t}$ are equal to the reservoir pressure and enthalpy.

The downstream boundary condition is more complicated. Two cases are possible. The first case is for subsonic flow throughout the duct. The boundary condition in this case is specified by equating the exit static pressure of the last component with the receiver pressure.

The second case is for a choke point occurring at some point in the duct. The boundary condition for this situation is specified by equating $\omega$ with the sonic value of the Crocco number, $\omega^{*}$, at the choke point. The location of the choke point must be found as part of the solution.

\section{Solution of the DUCTFLO Equations}

It is not known a priori if the flow is choked or unchoked. An iterative shooting scheme is adopted to determine which downstream boundary condition is appropriate. The inlet Crocco number into the first component, $\omega_{0}$ is guessed. This along with the known total properties specifies the inlet flow conditions. $\varsigma$ and $q$ are evaluated for the first component based on the inlet flow conditions. Equation III-1 is solved for $\omega_{I}$. Equations II1 and II-5 are solved for the outlet total properties. This specifies the inlet flow conditions to the second component. This procedure is repeated for the remaining components (i.e., $I=2,3, \ldots N)$. When the last component is reached, the component exit pressure is compared with the receiver pressure. If the exit pressure is greater than the receiver pressure, the solution procedure is started over with a slightly larger guess of $\omega_{0}$. This is repeated until the exit pressure from the last component equals the receiver pressure or 
until a choked point is found. A chokepoint is found by comparing $\omega_{I}(I=1,2,3 \ldots N)$ with $\omega^{*}$. If $\omega_{I}$ equals $\omega^{*}$ the flow is choked at the exit of component $I$. The correct solution is found by using a low value of the initial guess of $\omega_{0}$. Subsequent increases in the guess of $\omega_{0}$ are kept small. This prevents finding a choke point prematurely.

\section{Discussion of TOPAZ}

\section{Introduction}

TOPAZ (Transient Qne-Dimensional Pipe Flow Analyzer) is a highly general finite difference code for modeling the flow of compressible and incompressible fluids through complex and arbitrary arrangements of pipes, valves, flow branches and vessels. Fluid flow is modeled as one-dimensional and transient. Heat exchange between the flowing fluid and surrounding containment (vessel and pipe walls) can also be modeled, as well as two-dimensional-transient heat conduction in the containment itself. A more detailed description of TOPAZ is given in reference [11]. The discussion in this section will be restricted to the methods used in altering the fluid flow difference equations to include empirical total pressure and enthalpy loss data.

The fluid flow difference equations in TOPAZ result from applying a "displaced mesh" upwind finite difference scheme to the flow conservation equations. This has the effect of eliminating space as an independent variable. The three partial differential equations for flow continuity, energy, and momentum are replaced by a much larger set of ordinary differential equations with time as the dependent variable. The particular scheme used to spatially discretize the PDE'S is explained in references [3] and [4] but is similar to most upwind finite difference methods applied to fluid flow, including those methods applied to two- and three-dimensional flow. The flow field is divided into control volumes across which upwind finite difference forms of the continuity and energy equations are applied. A set of finite difference momentum equations is written to describe the flow at each control volume boundary. Hence, the differencing conserves continuity and energy over control volumes and momentum at control volume interfaces. The term "displaced mesh" is used here to indicate that the spatial or axial locations where the finite difference momentum equation 
are applied are "displaced" from the locations where the finite difference continuity and energy equations are applied.

Despite the incorporation of the displaced mesh, the TOPAZ fluid flow finite difference equations can still be used to model flow through discreet components in much the same way as the "fixed mesh" code DUCTFLO, thus making it possible to incorporate empirical total pressure and enthalpy loss data directly into code calculations. In those situations in which the total pressure and enthalpy losses across a complex flow component are known, the need to model the component with a fine mesh (i.e., many control volumes) disappears. Both DUCTFLO and TOPAZ model such components as a single control volume. Quasisteady flow through the component is completely described using the empirical data and the three differenced conservation equations for continuity, energy, and momentum.

"Empirical component modeling" in TOPAZ can best be explained using the illustration in Figure 2. Shown are three separate components in series. Associated with each component is a single control volume and an upstream control volume interface. The component control volumes are designated by $I-1, I$, and $I+1$ while the associated control volume interfaces are designated by $J-1, J$, and $J+1$.

In order to understand how the TOPAZ finite difference equations must be altered to include empirical total pressure and enthalpy loss data, we shall focus our attention on a typical component, in this case the component in the center of Figure 2 . Because of upwind differencing, flow enters the component control volume at state $I-1$ and exits at state $I$. The three TOPAZ equations used to describe flow through this component are given in reference [11] and repeated here for convenience:

$$
\begin{array}{rlr}
\text { Continuity : } & \frac{d M_{I}}{d t}=W_{J}-W_{J-1} & (I V-1) \\
\text { Energy : } & \frac{d}{d t}\left[\rho V\left(u+\frac{1}{2} v^{2}\right)\right]_{I}=V_{I} \dot{q}_{v}+W_{J}\left[h+\frac{1}{2} v^{2}\right]_{I-1} & (I V-2) \\
& -W_{J+1}\left[h+\frac{1}{2} v^{2}\right]_{I} & \\
\text { Momentum : } & I_{J} \frac{d W_{J}}{d t}=\left(P+\rho v^{2}\right)_{I-1}-\left(P+\rho v^{2}\right)_{I}-\frac{K\left(\rho v^{2}\right)_{J}}{2} & (I V-3)
\end{array}
$$




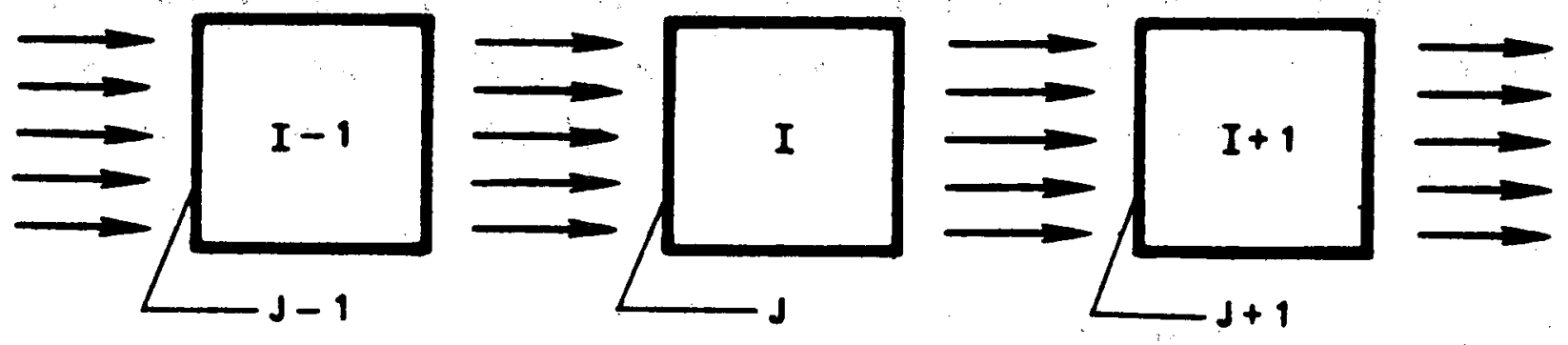

Figure 2. TOPAZ nodalization for components 
Equations (IV-1) through (IV-3) employ the nomenclature suggested by Figure 2. They are identical to the original TOPAZ equations presented in reference [11] with the following exceptions:

1. The quantity $u+P / \rho$ is replaced by $h$.

2. Wall heat transfer is neglected in the energy equation.

3. Wall friction is neglected in the momentum equation.

4. The effects of gravity are neglected.

The neglected terms would, of course, be accounted for in the total pressure and enthalpy loss data for the component. As explained below this data enters the TOPAZ equations through the form loss. function, $K$, and the volumetric heat generation rate function, $\dot{q}_{\boldsymbol{v}}$.

\section{Incorporating Total Pressure Loss Data}

In order to be consistent with the presentation given in Section II, it shall be assumed that the available total pressure loss data is given in the following form:

$$
K_{t}=\frac{\left(P_{t}\right)_{I-1}-\left(P_{t}\right)_{I}}{\left(\rho v^{2} / 2\right)_{J}}
$$

where $K_{t}$ is a form loss function based on the total pressure drop across the component.

Assuming quasi-steady flow (i.e. $d / d t=0$ and $W_{J-1}=W_{J}=W_{J+1}$ ) equation (IV-3) can be solved for the TOPAZ form loss function $K_{J}$ :

$$
K_{J}=\frac{\left(P+\rho v^{2}\right)_{I-1}-\left(P+\rho v^{2}\right)_{I}}{\left(\rho v^{2} / 2\right)_{J}}
$$

In examining equations (IV-4) and (IV-5) it becomes apparent that the two definitions for form loss function can be inconsistent. For low $M a, K_{J} \rightarrow K$ and in the incompressible limit $(M a=0), K_{J}=K$. However, for highly compressible flows, say $M a>$ 0.3 , significant error could result if $K_{t}$ and $K_{J}$ were used interchangeably in the TOPAZ momentum equation (III-3). In order to overcome this dilemma the usual TOPAZ momentum equation is replaced with the following alternate form: 


$$
I_{J} \frac{d W_{J}}{d t}=\left(P_{t}\right)_{I-1}-\left(P_{t}\right)_{I}-\frac{K_{J}\left(\rho v^{2}\right)_{J}}{2}
$$

Under quasi-steady flow conditions, the definitions for the form loss functions in equations (IV-4) and (IV-6) are identical. Hence by replacing the usual TOPAZ momentum equation with equation (IV-6), it is possible to directly incorporate component total pressure loss data given in the form of equation (IV-4).

\section{Incorporating Total Enthalpy Loss Data}

In order to be consistent with the presentation given in Section 2 , it shall be assumed that the available total enthalpy loss data is given in the following form:

$$
q=\frac{\left(h_{t}\right)_{I}-\left(h_{t}\right)_{I-1}}{\left(h_{t}\right)_{I}}
$$

where the definition of total enthalpy is given by equation (II-4).

Assuming quasi-steady flow and employing the total enthalpy definition, the TOPAZ energy equation (IV-2) reduces to the following form:

$$
\dot{q}_{v}=\frac{\left.W \backslash\left(h_{t}\right)_{I}-\left(h_{t}\right)_{I-1}\right\rfloor}{V_{I}}
$$

Substituting (IV-7) into (IV-8) yields the following function for $\dot{q}_{v}$ in terms of the available total enthalpy loss function $q$ :

$$
\dot{q}_{v}=q W\left(h_{t}\right)_{I-1} / V_{I}
$$

When the above equation for $\dot{q}_{v}$ is substituted into the energy equation (IV-2), the empirical total enthalpy loss data can be fully incorporated into TOPAZ quasi-steady calculations. 

V. Comparison of DUCTFLO and TOPAZ Calculations.

\section{Test Problem}

A test problem was formulated to verify that both DUCTFLO and TOPAZ are capable of incorporating empirical quasi-steady total pressure and enthalpy loss data into time dependent gas flow calculations. The geometry for the test problem is schematically represented in Figure 3. At time zero the high pressure gas located in the upstream reservoir is allowed to flow through seven individual components to the low pressure receiver. An ideal gas equation of state is assumed. The initial conditions for the reservoir are listed in Table I. Each of the seven components are assumed to have an experimentally obtained form loss function as a function of inlet $M a$ given by

$$
K_{t}=\frac{1}{C}\left[1-\frac{1}{(\gamma-1) M a^{2}}+1\right]^{-N}
$$

and a constant enthalpy loss factor $q$. Values for $q, C$, and $N$ are given in Table II for each of the seven components. Table II also contains a listing of the effective diameters for each component. Component diameters and losses were deliberately selected so that choked flow would occur well upstream of the receiver entrance. If the two codes properly account for the empirical total pressure and enthalpy losses, then each code should identify the location of the choke point and the time at which choking and unchoking occurs. Code predictions for the state and quantity of gas in the vessels should also compare well throughout the gas transfer.

\section{Calculational Results}

Both DUCTFLO and TOPAZ predicted flow choking at the expansion between components 4 and 5 . Each code predicted that unchoking occurs at a time 0.13 seconds after transfer begins.

The reservoir and receiver pressure, temperature, and mass inventory predicted by DUCTFLO and TOPAZ are presented in Figures 4 through 6 . The comparison is excellent throughout the entire transfer. The fact that DUCTFLO models the transfer using 


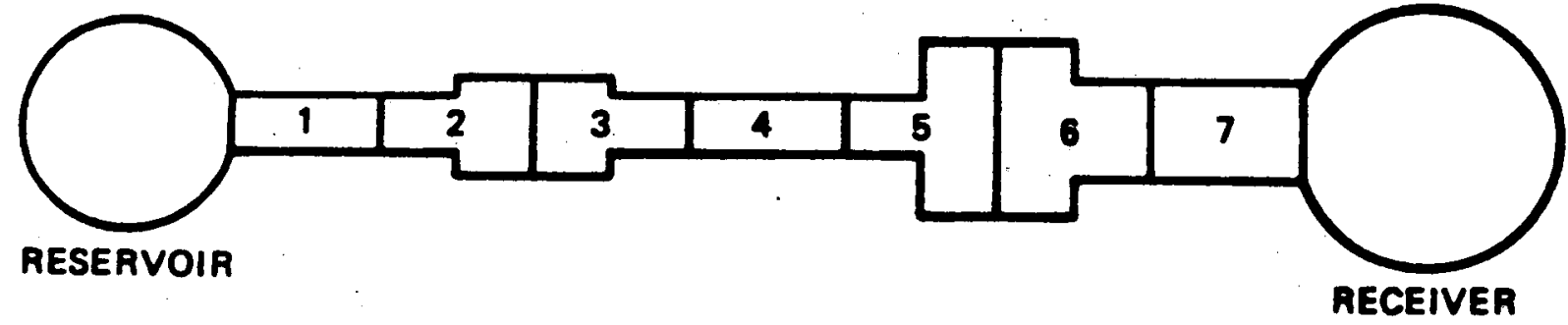

Figure 3. Example problem schematic 
Table I. Reservoir/Receiver Parameters for Example Problem

PARAMETER RESERVOIR RECEIVER

$\begin{array}{ccc}\text { Volume } & 30 \mathrm{cc} & 3000 \mathrm{cc} \\ \text { Initial Pressure } & 300 \mathrm{~atm} & 0.1 \mathrm{~atm} \\ \text { Initial Temperature } & 300^{\circ} \mathrm{K} & 300{ }^{\circ} \mathrm{K} \\ \text { Gas } & \mathrm{H}_{2} & \mathrm{H}_{2} \\ \text { Heat Transfer } & \text { adiabatic } & \text { adiabatic }\end{array}$


Table II. Loss Parameters for Example Problem

\begin{tabular}{|c|c|c|c|c|c|}
\hline $\begin{array}{c}\text { COMPONENT } \\
\text { NUMBER }\end{array}$ & $\begin{array}{c}\text { INLET DIA. } \\
\mathrm{cm}\end{array}$ & $\begin{array}{c}\text { OUTLET DIA. } \\
\mathrm{cm}\end{array}$ & $\mathrm{C}$ & $\mathrm{N}$ & $q$ \\
\hline 1 & 0.1524 & 0.1524 & 0.3 & 0 & 0 \\
2 & 0.1524 & 0.1669 & 0.25 & 1 & -0.1 \\
3 & 0.1669 & 0.1493 & 0.25 & 2 & -0.05 \\
4 & 0.1493 & 0.1493 & 0.1 & 3 & +0.2 \\
5 & 0.1493 & 0.4721 & 0.8 & 2 & 0 \\
6 & 0.4721 & 0.3657 & 0.8 & 1 & 0 \\
7 & 0.3657 & 0.3657 & 0.9 & 0 & 0 \\
\hline
\end{tabular}


VESSEL PRESSURES

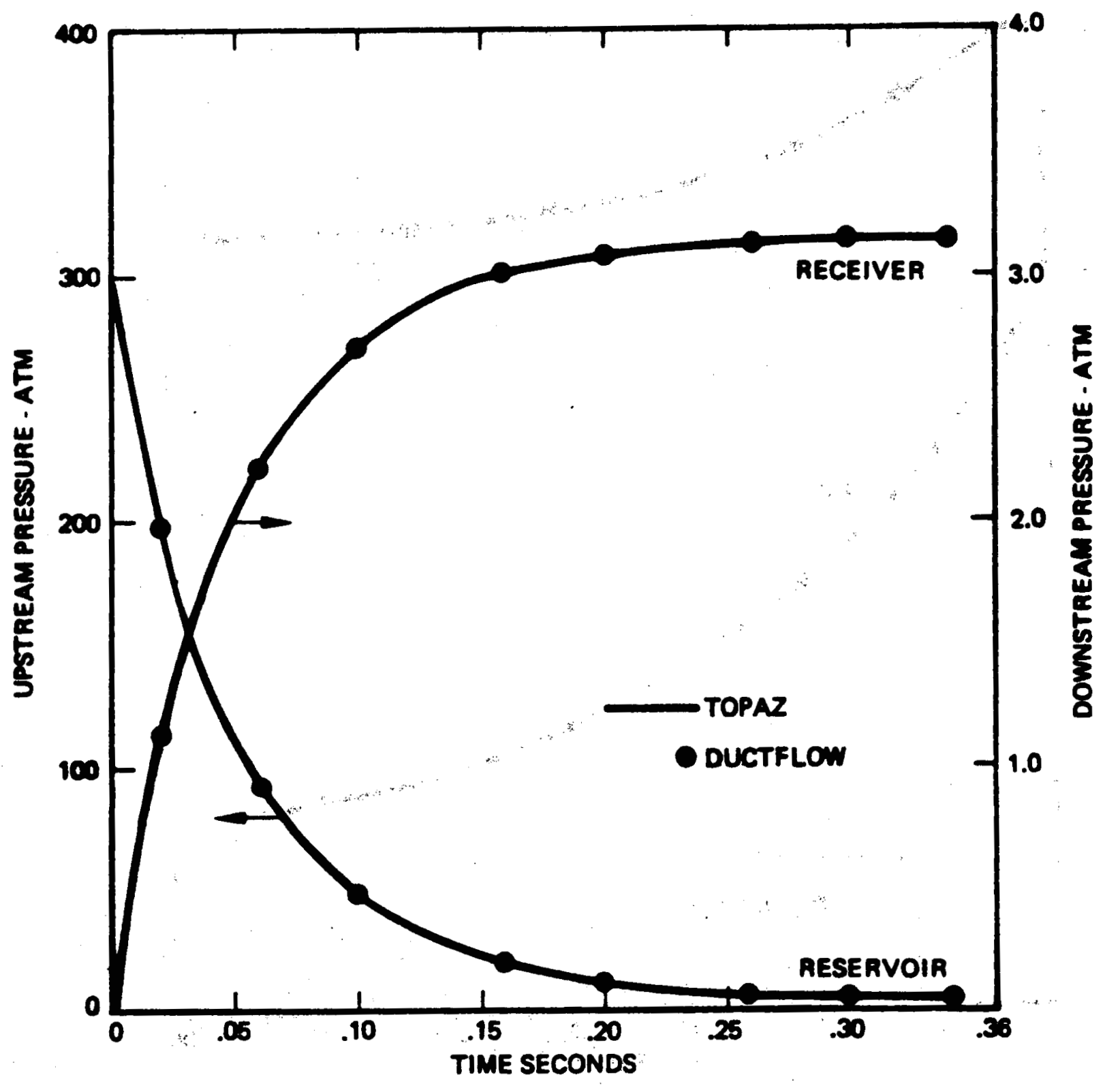

Figure 4. Vessel pressure histories for example problem 


\section{VESSEL TEMPERATURES}

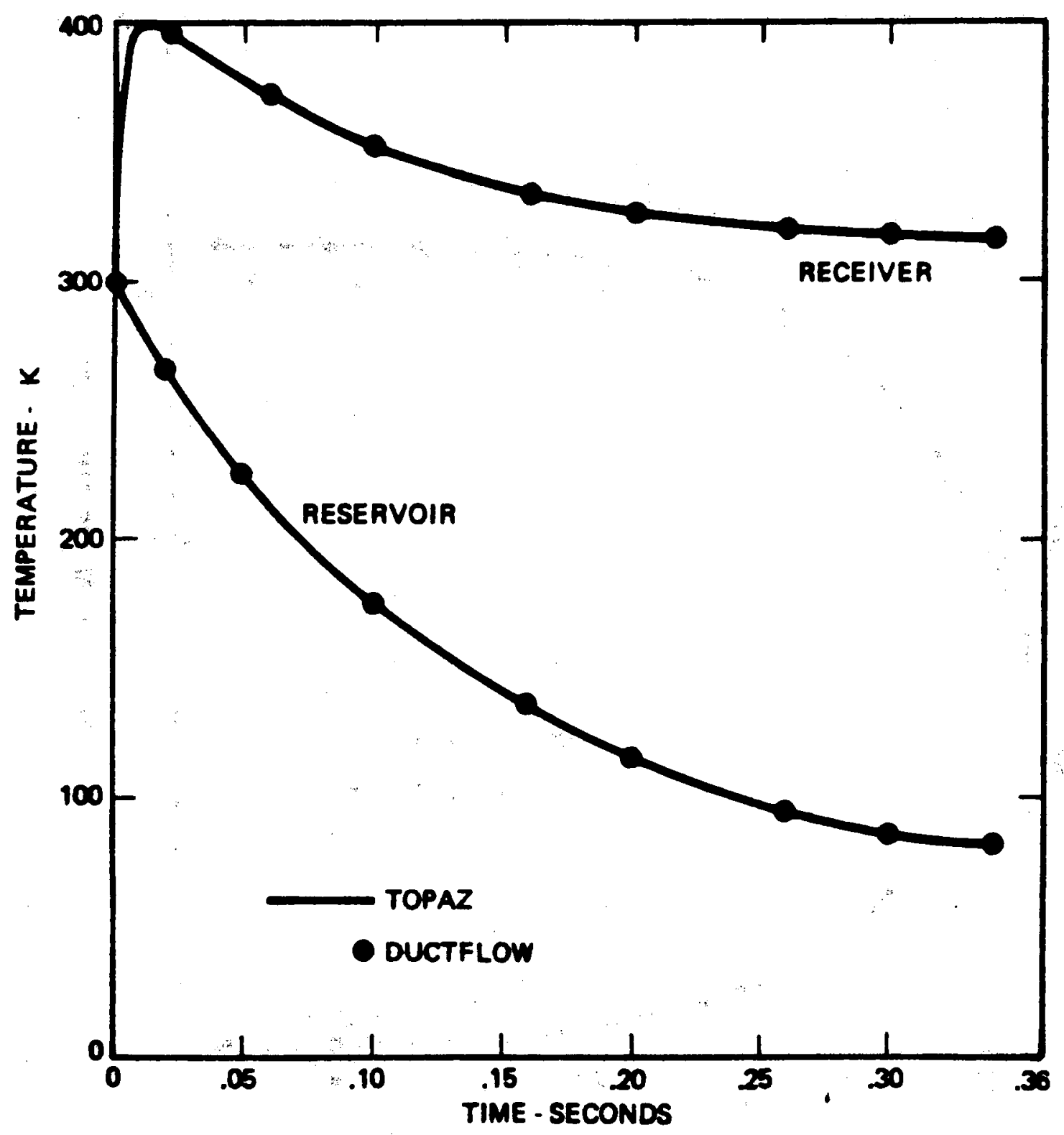

Figure 5. Vessel temperature histories for example problem 


\section{VESSEL MASSES}

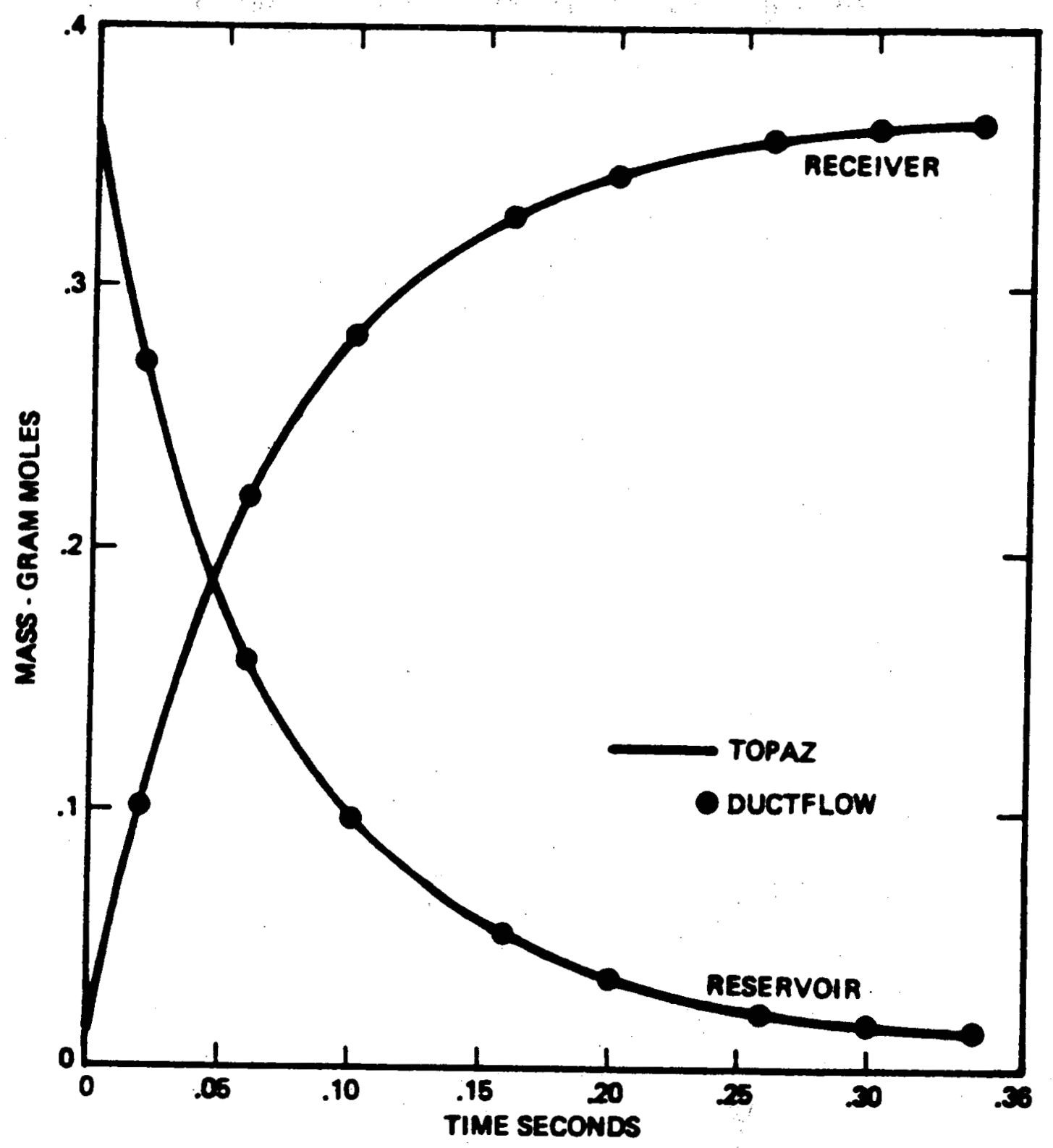

Figure 6. Vessel mass inventories for example problem 
steady equations while TOPAZ uses unsteady equations appears to be unimportant. Each code accurately reproduces the quasi-steady empirical total pressure and enthalpy loss characteristics for all seven components over the entire length of the simulated transfer. 


\section{References}

1. Chenoweth, D. R., "Gas-Transfer Analy sis Section G-Gas Flow in Real Duct Systems," SAND79-8212, Sandia National Laboratories, Livermore, CA, 1979.

2. Shapiro, A. H., The Dynamics and Thermodynamics of Compressible Fluid Flow, 1, John Wiley and Sons, New York, 1953.

3. Moore, R. V., et al., "RETRAN - A Program for One-Dimensional- Transient Thermal-Hydraulic Analysis of Complex Fluid Flow Systems, Volume : Equations and Numerics", EPRI NP-407, Energy Incorporated, P. O. Box 736, Idaho Falls, Idaho 83401, January 1977.

4. RELAP4/MOD5, A Computer Program for Transient Thermal-Hydraulic Analysis of Nucleat Reactors and Related System, Users' Manual, ANCR-NUREG-1355, Idaho National Engineering Laboratory, September 1976.

5. Ransom, V. H. and Wagner, R. J., et al., "RELAP5/MOD1 Code Manual Volume 1: System Models and Numerical Methods," NUREG/CR-1826, EG\&G Idaho, Inc., Idaho Falls, Idaho 83415, March 1981.

6. Moody, L. F., "Friction Factors for Pipe Flow," Trans. ASME, 66, No. 8, p. 671, 1944.

7. Dittus, F. W. and Boelter, L. M., University of California (Berkeley) Pub. Eng., 2, p. $443,1930$.

8. Flow of Fluids Through Valves, Fittings, and Pipe, Technical Paper No. 410, Crane Co., New York, NY, 1980.

9. Lamb, O. P., and Holdhusen, J. S., "Investigation of Aircraft Ducting Components at High Subsonic speeds," WADC Technical Report 56-187, September 1956.

10. Clark, G. L., "A Zero-Dimensional Model of Compressible Gas Flow in Networks of Pressure Vessels - Program TRIC", SAND83-8226, Sandia National Laboratories, Livermore, CA, July 1983.

11. Winters, W. S., "TOPAZ - A Computer Code for Modeling Heat Transfer and Fluid Flow in Arbitrary Networks of Pipes, Flow Branches, and Vessels," SAND83-8253, Sandia National Laboratories, Livermore, CA, 1984. 
12. Chenoweth, D. R., "Gas-Transfer Analysis Section H - Real Gas Results via the van der Waals Equation of State and Virial Expansion Extensions of its Limiting Abel-Noble Form," SAND83-8229, Sandia National Laboratories, Livermore, CA 1983. 


\title{
UNLIMITED RELEASE
}

\section{INITIAL DISTRIBUTION}

J. W. Nunziato, 1510

J. C. Cummings, 1512; Attn: F. G. Blottner, 1512

R. S. Claassen, 8000; Attn: D. L. Hartley, 8300

R. C. Wayne, 8400

D. M. Olson, 8100; Attn: J. D. Gilson, 8130

W. E. Alzheimer, 8150

D. J. Bohrer, 8160

\begin{abstract}
A. S. Rivenes, 8162
\end{abstract}
W. G. Wilson, 8163

A. N. Blackwell, 8200

W. D. Wilson, 8230

R. J. Kee, 8231

M. I. Baskes, 8233

G. L. Clark, 8233

C. W. Robinson, 8240; Attn: $\quad$ G. A. Benedetti, 8241

M. L. Callabresi, 8242

M. R. Birnbaum, 8243

C. M. Hartwig, 8244

C. E. Hackett, 8244

M. P. Kanouff, 8244 (10)

B. A. Meyer, 8244

D. R. Chenoweth, 8245

G. H. Evans, 8245

M. E. John, 8245

S. Paolucci, 8245

W. S. Winters, 8245 (10) 
P. L. Mattern, 8350

S. C. Johnston, 8351

B. R. Sanders, 8363

L. D. Bertholf, 8430

M. Abrams, 8431

H. Hanser, 8440

A. J. West, 8441

W. R. Hoover, 8442

E. T. Cull, 8445

A. Lutz, 8445

Publications Division 8265/Technical Library Processes Division, 3141

Publications Division, for TIC (27)

Technical Library Processes Division, 3141 (3)

M. A. Pound, 8242-2, for Central Technical Files (3) 